\title{
MALE HEMOLYMPH LoSS DURING NuPTIAL FeEding AS A ProXimate Mechanism UNDERLYING THE ViRgin-MALE MATING AdVANTAGE IN SAGEBRUSH CRICKETS
}
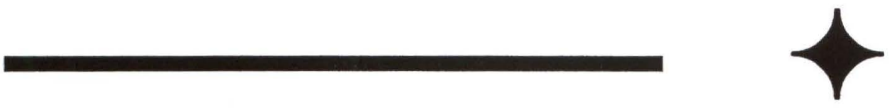 \\ SCOTT K. SAKALUK $\uparrow$ MARK T. H. CAMPBELL $\uparrow$ PETER A. KEORPES \\ BEHAVIOR, ECOLOGY, EVOLUTION AND SYSTEMATICS SECTION \\ DEPARTMENT OF BIOLOGICAL SCIENCES \\ ILLINOIS STATE UNIVERSITY $\uparrow$ NORMAL \\ ANDREW P. CLARK $\uparrow$ DEPARTMENT OF PSYCHOLOGY \\ MCMASTER UNIVERSITY $\downarrow$ HAMILTON $\downarrow$ ON $\downarrow$ CANADA
}

\begin{abstract}
$\uparrow \quad$ ABSTRACT
Male sagebrush crickets, Cyphoderris strepitans, offer an unusual nuptial food gift to females during mating: females chew on the ends of the males' fleshy hind wings and ingest hemolymph seeping from the wounds they inflict. Previous studies have shown that once a male had mated, his probability of obtaining an additional copulation is reduced relative to that of a virgin male seeking to secure his first mating, a pattern known as the virginmale mating advantage. One hypothesis to account for the virgin-male mating advantage is that nonvirgin males, having lost a substantial portion of their energy reserves at mating, may be unable to sustain the costly acoustical signaling activity required for the passive attraction of additional females. If the future mating prospects of non-virgin males are diminished because of sexual fatigue, this could stem either from the resources required to manufacture a new spermatophore or through the energy needed to replenish haemolymph lost through female wingfeeding. To distinguish between these two alternatives, we experimentally depleted virgin males of varying amounts haemolymph $(0,5$ and $10 \mu \mathrm{l})$ in a way that mimicked hemolymph loss of non-virgin males,
\end{abstract}

without the attendant costs of spermatophore production. After they had been treated, males were released in the field and recaptured over the course of the breeding season to monitor their mating success. Control males mated significantly sooner than did males depleted of 5 or $10 \mu \mathrm{l}$ of hemolymph. We conclude, therefore, that the depletion of hemolymph that occurs through female wing feeding is sufficient by itself to diminish a non-virgin male's ability to secure another mating, acting as a brake on the operation of sexual selection in this species.

\section{$\uparrow \quad$ INTRODUCTION}

The sagebrush cricket, Cyphoderris strepitans, is one of only five extant species belonging to an obscure orthopteran family, the Haglidae, and occurs exclusively in mountainous areas of the western United States, where it is found primarily in high-altitude sagebrush meadow habitat (Morris and Gwynne, 1978). Adults become sexually active in late spring, shortly after the snow melts, and remain active for the next 4-6 weeks. The acoustic signals produced by males function to attract females (Snedden and Irazuzta, 1994), and appear to be the 
principal means of pair formation (Snedden and Sakaluk, 1992; Sakaluk et al., 1995a). Copulation is initiated when a receptive female climbs onto the dorsum of a male, at which time he attempts to transfer a spermatophore. During copulation, the female feeds on the male's fleshy hind wings and bodily fluids (hemolymph) leaking from the wounds she inflicts (Dodson et al., 1983; Eggert and Sakaluk, 1994; Sakaluk et al., 1995b).

An earlier study involving the markrecapture of a large number of males showed that once a male had mated, his probability of obtaining an additional copulation was reduced relative to that of a virgin male securing his first mating (Morris et al., 1989). This "virgin-male mating advantage" subsequently has been confirmed in field studies conducted over two consecutive breeding seasons and designed to measure lifetime male mating success (Snedden, 1995, 1996).

One explanation for the virgin-male mating advantage is that non-virgin males, having lost a substantial portion of their energy reserves through sexual cannibalism by females and the transfer of a spermatophore, may be unable to sustain the costly acoustical signaling activity required for the passive attraction of additional females. In support of the "sexual fatigue" hypothesis, electronic assays of male signaling behavior have shown that virgin male $C$. strepitans call for significantly longer durations than recently mated males, at least in the short term (Sakaluk et al., 1987; Sakaluk and Snedden, 1990); to what extent differences in calling account for differential mating success, however, remains unknown. An alternative hypothesis to account for the virgin-male mating advantage is that females preferentially mate with virgin males, because these males potentially have greater material resources to offer females than do non-virgin males. If the acoustic structure of males' signals were systematically altered by the loss of hind-wing material underlying the sound-producing tegmina, then females could potentially discriminate against mated males through reduced phonotaxis to their calls. However, a field study in which the hind-wing material of virgin males was experimentally ablated (controlling for hemolymph loss) failed to reveal any effect of the treatment on male mating success, a result that is inconsistent with an acousticallymediated mating preference (Sakaluk and Ivy, 1999).

If the future mating prospects of non-virgin males are diminished because of sexual fatigue, this could stem either from the resources required to manufacture a new spermatophore or through the energy needed to replenish haemolymph lost through female wing-feeding. The relative costs of producing new spermatophores versus hemolymph replenishment are unknown; in mating trials staged in the laboratory, males are capable of producing two spermatophores within a night even when held without food (Eggert and Sakaluk, 1994; Sakaluk and Ivy, 1999), which suggests that spermatophore production does not constitute a major constraint. One difficulty in distinguishing between these alternatives is that non-virgin males are invariably disadvantaged in both contexts. In the current study, we circumvented this problem by experimentally depleting virgin males of haemolymph in a way that mimics hemolymph loss of non-virgin males, without the attendant costs of spermatophore production. If the resources devoted to the replenishment of hemolymph come at the expense of energy devoted to calling, the experimental depletion of hemolymph in virgin males should lead to a reduction in their mating success relative to unmanipulated virgin males.

\section{$\downarrow \quad$ MeTHODS}

A mark-recapture study was conducted from May 21 to June 15, 2003 in Grand Teton National Park, Wyoming. A rectangular study plot of approximately three ha was established in sagebrush meadow habitat adjacent to the Snake River at Deadman's Bar. During the early portion of the breeding season, we attempted to capture and mark all of the virgin males present in the study plot. Males were found at night by orienting to their calls and using head lamps to determine their exact location within a sagebrush bush. The mating status of males was determined by examining their hind wings for the wounds inflicted by females; only virgin males, as evidenced by intact wings, were used in experimental treatments. Each virgin male was placed in a collecting vial, numbered to correspond with a surveyor's flag placed at the capture location, and transported to the University of WyomingNational Park Service Research Center, approximately $30 \mathrm{~km}$ away, for processing.

Captured males were randomly assigned to one of three treatments in which males were experimentally depleted of hemolymph to varying degrees: 1) males from which $5 \mu$ of hemolymph were drawn, 2) males from which $10 \mu$ l of hemolymph were drawn, and 3) sham-operated control males. Hemolymph was extracted from males by making a small incision in the outside margin of one of the hind wings (usually the right), and drawing 
hemolymph from the wound using a microhematocrit capillary tube (Weddle and Sakaluk, 2003). In sham-operated control males, a small incision was made in the hind wing of the male resulting in minimal or no hemolymph loss. This treatment was established as a control for any detrimental effects of handling/surgery experienced by males in the other two treatments. Each male was marked individually with a numbered plastic tag secured to the pronotum with cyanoacrylic glue, and his femora painted with fluorescent model paint (Testors ${ }^{\circledR}$ ) of a unique color that designated the treatment to which he had been assigned. Portable ultraviolet lanterns, the illumination of which caused the paint to fluoresce in the dark, were used to facilitate the capture of experimental individuals at night. The following evening at sunset, marked males were returned to their respective points of capture. We marked and released a total of 121 males (40 sham-control, 40 five- $\mu$ l hemolymph-depleted males, 41 ten- $\mu$ l hemolymph-depleted males) over the course of six nights (May 21-26).

After experimental males had been released, males were recaptured and examined for evidence of mating activity regularly over the course of the breeding season, usually every second night, weather permitting. We recaptured, on the average, $30.0 \pm 5.6$ males $( \pm \mathrm{SE})$ on any given night (range $=8-61, N=$ 12 nights). Mating activity was inferred by loss of hind wing material in all treatments. Wing wounds were classified as "fresh" (visibly wet wounds with no discoloration indicating that the male had mated on the night of capture) or "old" (dry, darkened wounds indicating that the male had mated at least one night previous to the night of capture).

Institute, 2000).

Data were analyzed using SAS (SAS

\section{$\uparrow \quad$ RESULTS}

There was no difference between treatments in the initial mass of males following their capture (ANOVA: $\left.F_{2,118}=.97, p=.38\right)$ (Table 1). To compare the mass loss of males experiencing different levels of hemolymph depletion, we employed a Kruskal-Wallis nonparametric ANOVA because mass loss was non-normally distributed within treatments due to regurgitation of gut contents or defecation of some males during handling (Shapiro-Wilk test for normality, $p<0.05$ for all treatments). Hemolymph depletion resulted in a significant weight loss of experimental males prior to their release in the field (Kruskal-Wallis $\chi^{2}=75.1$, df
$=2, p<.0001)$ (Table 1). Post hoc pairwise comparisons using Mann-Whitney $U$ tests revealed that both $10-\mu \mathrm{l}(Z=-7.48, p<.0001)$ and $5-\mu \mathrm{l}$ hemolymph-depleted males $(Z=-7.03, p<.0001)$ lost more mass following treatment than did shamcontrol males, and that 10- $\mu$ l hemolymph-depleted males lost more mass than did 5- $\mu$ l hemolymphdepleted males $(Z=-3.02, p=.0034)$.

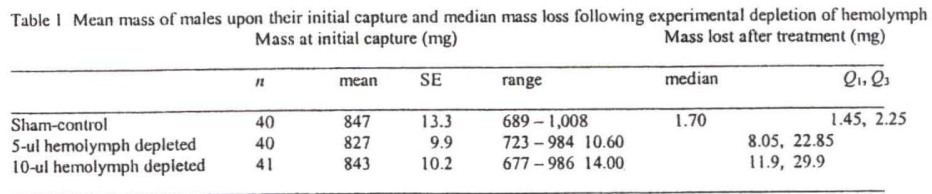

Eighty-four percent of marked males were recaptured at least once $(102 / 121)$, and there was no significant difference between treatments in the proportion of males recaptured (sham-control males: $82.5 \%$ (33/40); 5- $\mu$ l hemolymph-depleted males: $87.5 \%(35 / 40) ; 10-\mu l$ hemolymph-depleted males: $82.9 \%$ (34/41); Likelihood ratio $\left.\chi^{2}=0.48, p=0.17\right)$. To compare the number of times that males were captured over the course of the study (excluding those that were never recovered), we employed a Kruskal-Wallis nonparametric ANOVA because recapture frequencies were non-normally distributed within treatments (Shapiro-Wilk test for normality, $p$ $<0.05$ for all treatments). There were no significant differences in the number of times that males were recaptured across treatments (median recapture frequency (range); control $=3(1-8) ; 5-\mu l=3(1-8)$; $10-\mu \mathrm{l}=3(1-9) ;$ Kruskal-Wallis $\chi^{2}=2.13, \mathrm{df}=2, p=$ $.34)$.

Survival of experimental males was determined as the number of nights from the time a male was first captured to the night on which a male was last recaptured. We excluded from this calculation males that were never recovered following their initial release (see above) because these males may have lost their tags or immediately left the study area owing to the trauma of release. Males that were still alive on the last night of the study were treated as 'censored' observations. To compare survival across treatments, we employed failure time analysis (Fox, 1993). Failure-time analysis accommodates censored data, observations in which an event such as a male's death or mating may not have occurred by the end of the study, as was the case here. Omission of such data, as is frequently done in behavioral studies, may lead to a serious bias in comparisons across treatments (Fox, 1993). There was no difference in male survival across treatments (Wilcoxon $\chi^{2}=0.16, p=0.92$ ) (Figure 1). 


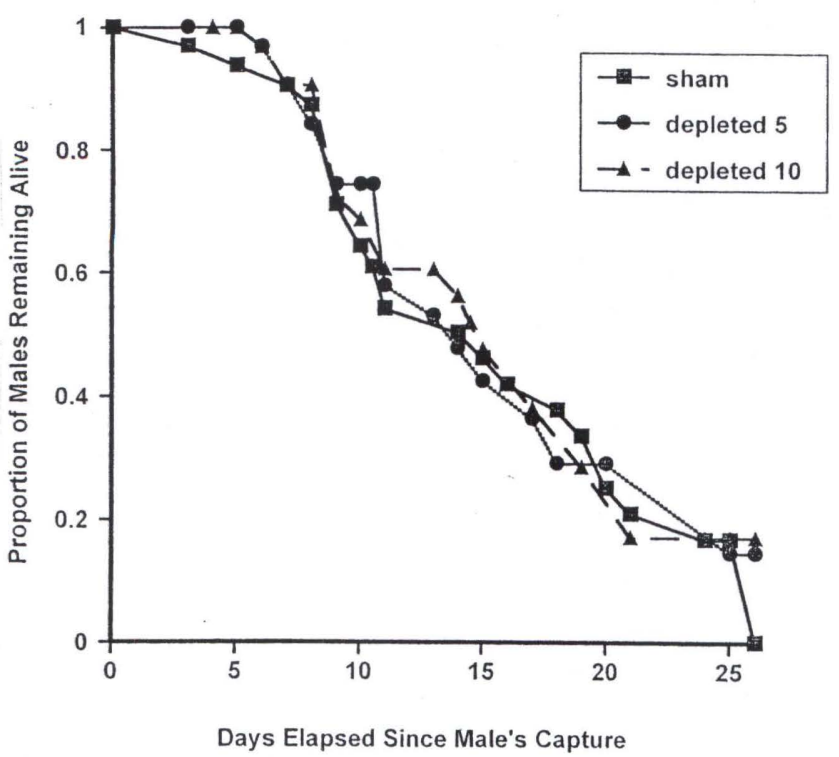

Figure 1. The proportion of male sagebrush crickets found alive as a function of the time elapsed since their initial capture. There was no difference in male survival across treatments (Wilcoxon $\chi^{2}=$ $0.16, p=0.92$ ).

Time to mating was determined as the number of nights from the time a male was first released until he was captured as a non-virgin. Nonvirgin males bearing fresh-wing wounds were assumed to have mated on the night they were captured. Non-virgin males bearing old-wing wounds were assumed to have mated at least one night previous to their capture or, if they had not been captured in the previous census, we recorded the night of mating as the mid-point of the earliest time they could have mated and the latest time they could have mated. Males that had still not mated by the time of their last capture were treated as 'censored' observations. We used failure time analysis to: 1) compare time to mating across all three treatments and 2) compare time to mating of control males with that of all hemolymph-depleted males combined. The first analysis showed no significant difference across treatments in the time taken by males to obtain their initial copulations (Wilcoxon $\chi^{2}=5.18, p=0.075$ ), but inspection of the data in Figure 2 reveals that the lack of a difference can be attributed more to the similarity in the trajectories of the $5-\mu l$ and $10-\mu l$ hemolymph-treatments, than to the absence of an effect of hemolymph depletion per se. This was confirmed by the second analysis, which showed that sham-control males mated significantly sooner than hemolymph-depleted males (Wilcoxon $\chi^{2}=5.06, p=$ 0.024 ). We might expect that as the study progressed, hemolymph-depleted males would have been able to require the resources required to replenish the hemolymph lost upon their initial treatment. In support of this possibility, the results shown in Figure
2 shows the greatest divergence in mating success of control males and hemolymph-depleted males in the first five days following males' release (dotted line in Figure 2) (Wilcoxon $\chi^{2}=6.08, p=0.013$ ); indeed, by this time $2 / 3$ of control males had mated (22/33), whereas less than half of the hemolymph-depleted males had mated by the fifth night following their release (31/69).

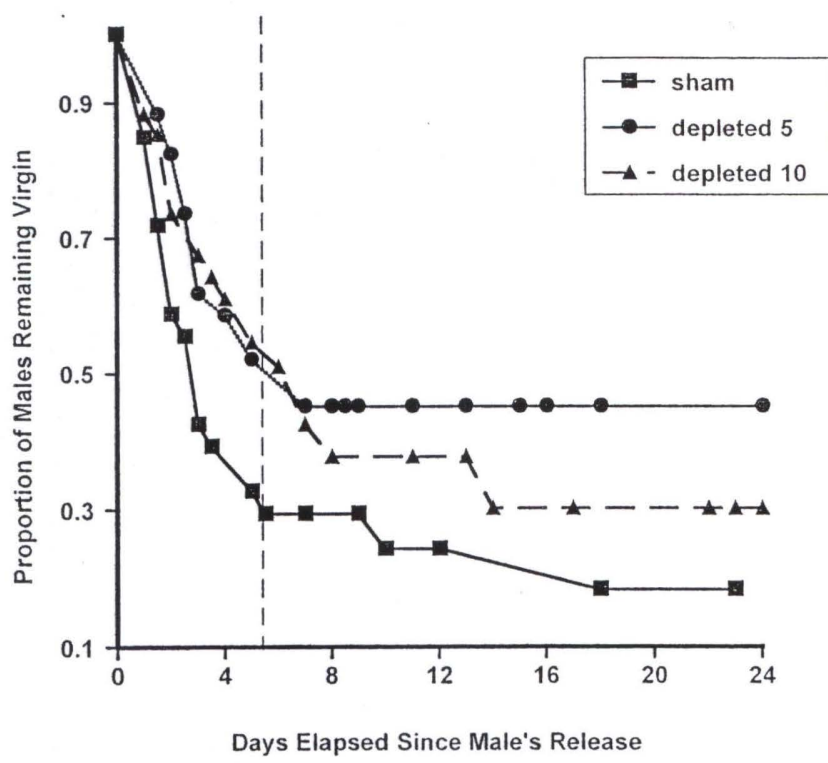

Figure 2. The proportion of male sagebrush crickets remaining unmated as a function of the time elapsed since their initial release. Sham-control males mated significantly sooner than hemolymphdepleted males (pooled) (Wilcoxon $\chi^{2}=5.06, p=0.024$ ). The dotted line marks the five-day interval following the males' release, the period during which the mating trajectories showed the most rapid divergence in the mating success.

\section{DISCUSSION}

Experimental depletion of hemolymph had a significant effect on the subsequent mating success of virgin male sagebrush crickets: control males mated significantly sooner than males depleted of 5 or $10 \mu \mathrm{l}$ of hemolymph. Although the precise amount of hemolymph ingested by females at mating is unknown, the experimental volumes encompass the approximate range of hemolymph ingested based on previous work. We conclude, therefore, that the depletion of hemolymph that occurs through female wing feeding is sufficient by itself to diminish a nonvirgin male's ability to secure another mating. When the costs of producing a new spermatophore are superimposed on the costs accrued via hemolymph lost at mating, it seems likely that sexual fatigue offers a better explanation for the virgin-male mating advantage documented in previous field studies 
(Morris et al., 1989; Snedden, 1995, 1996), than does any female preference for virgin males per se (see also Sakaluk and Ivy, 1999).

Although control males enjoyed a significant mating advantage, there was no discernible difference in the mating trajectories of the $5-\mu 1$ and $10-\mu l$ hemolymph-depleted males. It may be that there is a threshold for hemolymph depletion beyond which male investment in sexual advertisement is compromised irrespective of the level of depletion. Even in that case, however, we might expect that those males that had been more severely depleted would recover more slowly than those males experiencing a lower degree of depletion, but this was not evidenced by the mating trajectories of the $5-\mu \mathrm{l}$ and $10-\mu \mathrm{l}$ hemolymph-depleted males. In any event, males do appear to recover from hemolymph depletion as there was no differences in survival across treatments. Moreover, the greatest difference in the decline of the proportion of males remaining virgin occurred in the first five days following treatment, whereas the slopes of the trajectories for all three treatments were fairly similar after this interval.

Partly as a consequence of the virgin-male mating advantage, the opportunity for sexual selection in males appears to be reduced relative to species in which males make no such mating investments (Snedden, 1996). Given the constraints placed on a male's future mating potential by the loss of hemolymph and passage of the spermatophore in an initial mating, we might expect that males would be selective of prospective mating partners as has been documented in certain orthopteran species that exhibit a sex-role reversal (e.g., Gwynne, 1981; Gwynne and Simmons, 1990). However, unlike these other species, male $C$. strepitans invariably court any female with which they have been placed (pers. obs.), and we have never witnessed males rejecting females that have mounted them, either in the field or the laboratory. This suggests that notwithstanding the limited number of matings that males can expect to secure over their lifetime (Snedden, 1996), the Bateman gradient (i.e., the effect that mating success has on reproductive success; Arnold, 1994) is steeper in males than it is in females.

\section{ACKNOWLEDGEMENTS}

This research was conducted in Grand Teton National Park under the auspices of a Scientific Research and Collecting Permit (GRTE-2003-SCI0013) issued by the National Park Service. We thank
Steve Buskirk and Rich Viola of the UW-NPS Research Center for logistic support. This research was supported by grants from Illinois State University and the National Science Foundation (IBN-9601042, IBN-0126820) to S.K.S. M.T.H.C. and P.A.K. were supported by an NSF Research Experiences for Undergraduates supplemental award. A.P.C was supported by a travel award from the Department of Psychology at McMaster University, and a grant from the National Sciences and Engineering Research Council of Canada to Martin Daly.

\section{$\downarrow$ Literature Cited}

Arnold, SJ. 1994. Bateman's principles and the measurement of sexual selection in plants and animals. Am Nat 144 (Suppl):S126S149.

Dodson, G, GK Morris, and DT Gwynne. 1983. Mating behavior in the primitive orthopteran genus Cyphoderris (Haglidae). In: Orthopteran mating systems: sexual competition in a diverse group of insects, (Gwynne DT, Morris GK, eds). Boulder: Westview Press; 305-318.

Eggert A-K, and SK Sakaluk. 1994. Sexual cannibalism and its relation to male mating success in sagebrush crickets, Cyphoderris strepitans (Orthoptera: Haglidae). Anim Behav 47:1171-1177.

Fox, GA. 1993. Failure-time analysis: emergence, flowering, survivorship and other waiting times. In: Design and analysis of ecological experiments, (Scheiner SM, Gurevitch J, eds). New York: Chapman \& Hall; 253289.

Gwynne. DT. 1981. Sexual difference theory: Mormon crickets show role reversal in mate choice. Science 213:779-780.

Gwynne, DT, and LW Simmons. 1990. Experimental reversal of courtship roles in an insect. Nature 346:172-174.

Morris, GK, and DT Gwynne. 1978. Geographical distribution and biological observations of Cyphoderris (Orthoptera: Haglidae) with a description of a new species. Psyche 85: 147-167. 
Morris, GK, DT Gwynne, DE Klimas, and SK Sakaluk. 1989. Virgin male mating advantage in a primitive acoustic insect (Orthoptera: Haglidae). J Insect Behav 2:173-185.

Sakaluk, SK, and TM Ivy. 1999. Virgin-male mating advantage in sagebrush crickets: differential male competitiveness or non-independent female mate choice? Behaviour 136:13351346.

Sakaluk, SK, and WA Snedden. 1990. Nightly calling durations of male sagebrush crickets, Cyphoderris strepitans: size, mating and seasonal effects. Oikos 57:153-160.

Sakaluk, SK, GK Morris, and WA Snedden. 1987. Mating and its effect on acoustic signalling behavior in a primitive orthopteran, Cyphoderris strepitans (Haglidae): the cost of feeding females. Behav Ecol Sociobiol 21:173-178.

Sakaluk. SK, WA Snedden, KA Jacobson, and A-K Eggert. 1995a. Sexual competition in sagebrush crickets: must males hear calling rivals? Behav Ecol 6:250-257.

Sakaluk, SK, PJ Bangert, A-K Eggert, C Gack, and LV Swanson. 1995b. The gin trap as a device facilitating coercive mating in sagebrush crickets. Proc R Soc Lond B 261:65-71.

SAS Institute. 2000. SAS/STAT user's guide, version 8. Cary, North Carolina: SAS Institute.
Snedden, WA. 1995. Correlates of male mating success and their implications for sexual selection in a primitive orthopteran insect (PhD Dissertation). Toronto: University of Toronto.

Snedden, WA. 1996. Lifetime mating success in male sagebrush crickets: sexual selection constrained by a virgin male mating advantage. Anim Behav 51:1119-1125.

Snedden, WA, and S Irazuzta. 1994. Attraction of female sagebrush crickets to male song: the importance of field bioassays. J Insect Behav 7:233-236.

Snedden, WA, and SK Sakaluk. 1992. Acoustical signalling and its relation to male mating success in sagebrush crickets. Anim Behav 44:633-639.

Weddle, CB, and SK Sakaluk. 2003. Ingestion of male hemolymph and mating propensity of female sagebrush crickets: no evidence of a male-derived anti-aphrodisiac. Anim Behav 65:83-88. 